\title{
Demographic and clinical analysis of post sterilization failure cases in a tertiary care hospital, Chennai, Tamil Nadu, India
}

\author{
T. S. Meena ${ }^{1}$, K. S. Ramya ${ }^{1 *}$, R. Mothilal ${ }^{2}$ \\ ${ }^{1}$ Department of Obstetrics and Gynecology, ${ }^{2}$ Department of Family Welfare, Government Kilpauk Medical College
} Hospital, Chennai, Tamil Nadu, India

Received: 21 August 2017

Accepted: 16 September 2017

*Correspondence:

Dr. K. S. Ramya,

E-mail: drksramya@gmail.com

Copyright: $\odot$ the author(s), publisher and licensee Medip Academy. This is an open-access article distributed under the terms of the Creative Commons Attribution Non-Commercial License, which permits unrestricted non-commercial use, distribution, and reproduction in any medium, provided the original work is properly cited.

\begin{abstract}
Background: The most common permanent method of family planning accepted in India is female tubal sterilization as it has a very low failure rate of $0.1-0.8 \%$ in the first year and over all pregnancy chances of 1 in 200 . It can be done by open method but laparoscopic method has now gained wide popularity.

Methods: Ours was a retrospective study of post female sterilization failure cases admitted to the Department of Obstetrics and Gynecology, Government Kilpauk Medical College Hospital within a 10 year time period between April 2007 and March 2017.

Results: Over a decade we had 134 post sterilization failures. 71 patients presented with intrauterine pregnancy whereas 63 presented as ectopic pregnancy following sterilization. Majority of patients belonged to 26-30 year age group and the median age was 28 years. $40.3 \%$ ectopic presented at 5-6 weeks gestational age. Over $90 \%$ of sterilization failures were done by open method and around $35.8 \%$ were done during caesarean section. Around 65.0 $\%$ sterilization failures were seen within 5 years of sterilization but 2 patients presented as late as 17 years post sterilization. In four cases (3\%) failure was due to improper surgical procedure.

Conclusions: Female sterilization may result in failure even after years of sterilization. In the present study, pregnancy after sterilization is higher in the youngest age group (15-30) years than for the age group (31-35) years and stabilized in the oldest age group (36-49) years. Open sterilization had a higher failure rate than laparoscopic sterilization. The most common mode of sterilization failure was intrauterine pregnancy than the ectopic pregnancy and it was almost equal to each other. Therefore, patients undergoing sterilization must be counselled about chances of failure; even though it is a permanent method, and to consult immediately if missed period else at a later stage they may go in for rupture ectopic leading to high maternal morbidity and mortality.
\end{abstract}

Keywords: Female sterilization, Laparotomy, Post sterilization failure

\section{INTRODUCTION}

The most accepted family planning in India is tubal ligation of female which accounts for $65 \%$ of contraceptive use which is the highest all over the world. Almost 4-5 million sterilization procedures are performed annually contributing to $98 \%$ of all sterilizations. The most popular method used in female sterilization in Tamil Nadu is $(82 \%)$ postpartum sterilization after delivery.
More than half of the women are sterilised before 26 years which means that it provides protection for major part of their reproductive life. ${ }^{1}$ However unfortunately in some women sterilization failure may occur though rates are as low as around $0.1-0.3 \% .^{2}$

Post sterilization failure commonly presents as ectopic pregnancy and it accounts for around 12\% of all ectopic cases. ${ }^{3}$ Intrauterine pregnancy may also present in post 
sterilization failure cases. Ours being a tertiary care hospital, we have many referral cases of sterilization failures. Patients with rupture ectopic due to failed sterilization are of concern as it can lead to high maternal morbidity and mortality due to delayed diagnosis.

In present study, we have tried to evaluate the demographic pattern of women presenting post sterilization failure and the etiological factors for sterilization-failure and also to discuss preventive measures to avoid unwanted pregnancies and maternal morbidities as a result of sterilization-failure especially in developing countries like India where sterilization-failure is a genuine medical issue.

\section{METHODS}

This study is a retrospective cross-sectional study which includes all women who have reported or referred as tubal-sterilization-failure to Department of Obstetrics and Gynaecology, Postpartum centre, Family Welfare Division, Government Kilpauk Medical College and Hospital, Chennai-10 during the period of 10 years from April 2007 to March 2017.

Study cases of post sterilization failure were done from hospital records.

Demographic data regarding age and resident of patient and various parameters like parity, method of sterilization, time interval between sterilization and failure, mode of presentation and gestational age and time of sterilization whether concurrent or interval were analysed with MS-Excel and results tabulated. Similar method was used by Rathod $\mathrm{S}$ et al. on the Clinical analysis of post sterilization failure cases in a tertiary hospital. ${ }^{4}$

\section{Statistical analysis}

The statistical tools that proportion and percentage were used in discreet and continuous variable. Chi-square test was used. The statistical method that Correlation was used between age and interval of failure of post sterilisation cases.

\section{Chi-square test}

\section{Hypothesis I}

- H0: The attributes that age and interval of failure of post sterilization are independent

- H1: The attributes that age and interval of failure of post sterilization are not independent

There exists a relation between the age group that less than 30 years and 30 and above and interval of failure of post sterilization that (0-5) years and more than 5 years.
As the calculated chi-square value 17.7669 is greater than the table value of chi-square 3.84 , the null hypothesis may be rejected and the alternative hypothesis that the attributes that age of the patient and interval of failure of sterilization are dependent and statistically significant at p-value is $<0.05$ level of significance and degrees of freedom $=1$.

Table 1: The age and interval of failure of post sterilization.

\begin{tabular}{|c|c|c|c|c|}
\hline \multirow[b]{2}{*}{ Age } & \multicolumn{2}{|c|}{$\begin{array}{l}\text { Interval of failure } \\
\text { of post sterilization }\end{array}$} & \multirow[b]{2}{*}{ Total } & \\
\hline & $0-5$ & $\begin{array}{l}\text { More } \\
\text { than } 5 \\
\text { years }\end{array}$ & & \\
\hline $\begin{array}{l}\text { Less than } 30 \\
\text { years }\end{array}$ & 67 & 19 & 86 & \multirow{3}{*}{$\begin{array}{l}\text { Chi- } \\
\text { square= } \\
17.7669 \\
\text { P value } \\
0.00025\end{array}$} \\
\hline 30 and above & 20 & 28 & 48 & \\
\hline Total & 87 & 47 & 134 & \\
\hline
\end{tabular}

\section{Hypothesis II}

- H0: The attributes that age and mode of gestation of post sterilization are independent

- H1: The attributes that age and mode of gestation of post sterilization are not independent.

Table 2: The age and mode of gestation of the failure of post sterilization.

\begin{tabular}{|c|c|c|c|c|}
\hline \multirow[b]{2}{*}{ Age } & \multicolumn{2}{|c|}{ Mode of gestation } & \multirow[b]{2}{*}{ Total } & \\
\hline & $\begin{array}{l}\text { Spontaneous } \\
\text { recanalization }\end{array}$ & Ectopic & & \\
\hline $\begin{array}{l}\text { Less } \\
\text { than } 30 \\
\text { years }\end{array}$ & 50 & 36 & 86 & \multirow{3}{*}{$\begin{array}{l}\text { Chi- } \\
\text { square } \\
2.5606 \\
\text { P value } \\
0.106558\end{array}$} \\
\hline $\begin{array}{l}30 \text { and } \\
\text { above }\end{array}$ & 21 & 27 & 48 & \\
\hline Total & 71 & 63 & 134 & \\
\hline
\end{tabular}

As the calculated chi-square value 2.5606 is less than the table value of chi-square 3.84 , the null hypothesis that the age and mode of gestation that spontaneous recanalisation and ectopic pregnancy are independent and it may be accepted and the result is not significant at $\mathrm{p}$ value $<0.05$.

\section{RESULTS}

During the entire 10-year study period 15,712 female sterilization was done and 134 cases of post sterilization failure were reported out of which $71(53.0 \%)$ patients presented as intrauterine pregnancy whereas $63(47.0 \%)$ presented as ectopic pregnancy. In Figure 1, we display the time from female sterilization to pregnancy and the cumulative risk of contraceptive failure and it stabilised for the oldest age group (36-49) than for the two youngest age groups. 
According to Table 3, majority of patients belonged to age group 26-30 years and were gravida 3 . The median age of the post sterilization failure was 28 years.

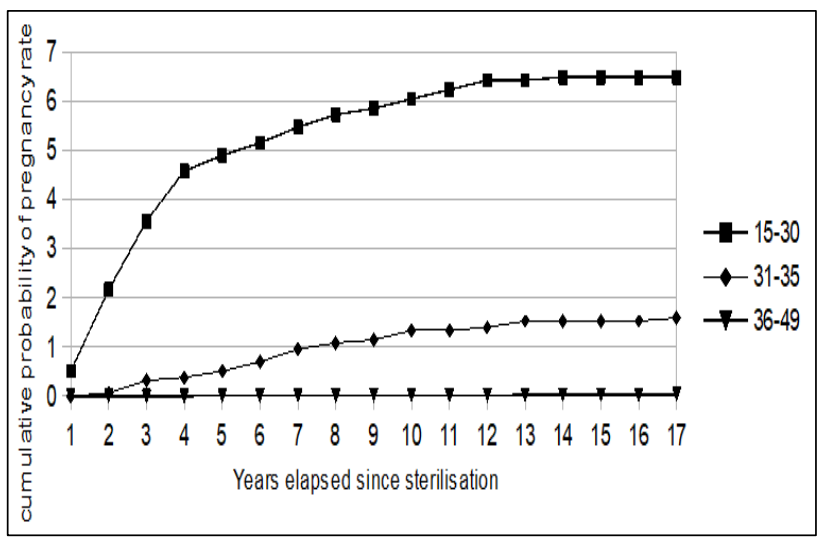

Figure 1: Time from female sterilization to pregnancy.
There was a positive correlation between the age of patient and the interval of post sterilization failure and it is significant since the $r$ value is 0.4 . The spatial distribution of the failure of sterilization case shows the rural urban participation was $20 \%$ and $80 \%$ respectively.

Open method was most commonly used $(91 \%)$ followed by Laparoscopic method (9\%) in post sterilization failure. Most of the ectopic pregnancies (96.8\%) presented between 5-8 weeks of gestation.

Around $65.0 \%$ presented as failure within 5 years of sterilization though 2 patients aged 35 and 40 years respectively presented almost 17 years after sterilization with ectopic. Out of the post sterilization failure cases, four cases $(3 \%)$ were due to improper procedure. In whom sterilization failure interval was <1year, initial non-occlusion due to improper procedure was responsible for failure in two of 8 cases $(25 \%)$.

Table 3: Parameters studied.

\begin{tabular}{|c|c|c|c|c|c|c|}
\hline & $\begin{array}{l}\text { Ectopic pregnancy } \\
\text { (No. of patients) }\end{array}$ & $(\%)$ & $\begin{array}{l}\text { Intrauterine pregnancy } \\
\text { (No. of patients) }\end{array}$ & $(\%)$ & Total & $\%$ \\
\hline \multicolumn{7}{|l|}{ Patients age in year } \\
\hline $20-25$ & 16 & 11.9 & 26 & 19.4 & 42 & 31.3 \\
\hline $26-30$ & 31 & 23.1 & 31 & 23.1 & 62 & 46.3 \\
\hline $31-35$ & 14 & 10.4 & 11 & 8.2 & 25 & 18.7 \\
\hline $36-40$ & 2 & 1.5 & 3 & 2.2 & 5 & 3.7 \\
\hline \multirow[t]{2}{*}{$41-45$} & 0 & 0 & 0 & 0 & 0 & 0 \\
\hline & 63 & 47 & 71 & 53 & 134 & 100 \\
\hline \multicolumn{7}{|l|}{ Gravida } \\
\hline 2 & 3 & 2.2 & 1 & 0.7 & 4 & 3 \\
\hline 3 & 45 & 33.6 & 51 & 38.1 & 96 & 71.6 \\
\hline 4 & 12 & 9 & 17 & 12.7 & 29 & 21.6 \\
\hline 5 & 1 & 0.7 & 2 & 1.5 & 3 & 2.2 \\
\hline 6 & 2 & 1.5 & 0 & 0 & 2 & 1.5 \\
\hline \multicolumn{7}{|l|}{ Gestational age } \\
\hline $3-4 w$ & 1 & 0.7 & 1 & 0.7 & 2 & 1.5 \\
\hline $5-6 w$ & 54 & 40.3 & 12 & 9 & 66 & 49.3 \\
\hline $7-8 w$ & 7 & 5.2 & 24 & 17.9 & 31 & 23.1 \\
\hline$>8 \mathrm{w}$ & 1 & 0.7 & 34 & 25.4 & 35 & 26.1 \\
\hline \multicolumn{7}{|l|}{ Method of sterilisation } \\
\hline Minilap/laparotomy & 59 & 44 & 63 & 47 & 122 & 91 \\
\hline Laparoscopic sterilisation & 4 & 3 & 8 & 6 & 12 & 9 \\
\hline \multicolumn{7}{|l|}{ Timing of sterilisation } \\
\hline Postpartum & 33 & 24.6 & 37 & 27.6 & 70 & 52.2 \\
\hline During LSCS & 22 & 16.4 & 26 & 19.4 & 48 & 35.8 \\
\hline Interval & 8 & 6 & 8 & 6 & 16 & 11.9 \\
\hline \multicolumn{7}{|c|}{ Interval between sterilisation and failure } \\
\hline$<1$ year & 2 & 1.5 & 6 & 4.5 & 8 & 6 \\
\hline $1-5$ & 35 & 26.1 & 44 & 32.8 & 79 & 59 \\
\hline $6-10$ & 20 & 14.9 & 15 & 11.2 & 35 & 26.1 \\
\hline$>10$ & 6 & 4.5 & 6 & 4.5 & 12 & 9 \\
\hline \multicolumn{7}{|l|}{ Spatial distribution } \\
\hline Rural & 14 & 10.4 & 13 & 10.8 & 27 & 20.1 \\
\hline Urban & 49 & 36.6 & 58 & 48.3 & 107 & 79.9 \\
\hline Total & 63 & 47 & 71 & 59.2 & 134 & \\
\hline
\end{tabular}




\section{DISCUSSION}

The incidence of failure of voluntary sterilization is rare about $0.13-1.3 \%$ of which ectopic gestation constitutes about $15-33 \% .^{2,5}$ In the present study, the incidence of failure of sterilization was $0.8 \%$ of which ectopic gestation constitutes about $47 \%$. The ectopic pregnancy rates in the US Collaborative Review of Female Sterilization Failure Working Group (CREST) study were $33 \% .{ }^{6}$ Case fatalities are increased in post sterilization failure ectopics mainly because of delay in considering it as a differential diagnosis. The incidence being more in open cases like minilap or during caesarean could be due to changes in anatomy during pregnancy which makes the tube edematous, friable and congested leading to incomplete tubal occlusion or due to fact that these procedures are mainly done by trainees. In the present study, most of the sterilization failure had interval between $1-10$ years as $85 \%$ but sterilization failures $(6 \%)$ presented in less than one year and $9 \%$ after 10 years in this study. Vessey et al also had sterilization failure interval between $1-10$ years as $85.7 \% .^{7}$

Defect in the surgical procedure or spontaneous recanalization may lead to sterilization failure. Tubal lumen regeneration occurs by tuboperitoneal fistula formation. This may be associated with features of PID, endosalpingitis, necrosis or tubal atrophy. It may also be associated with focal endometriosis when ligation site is within $4 \mathrm{~cm}$ of cornua. $^{7}$ Spontaneous tubal reapproximation, common in the postpartum period due to dilated tubes is associated with tubal reanastomosis and recanalisation. As a result of this blind pouches and slit like spaces are formed which causes ectopic implantation. ${ }^{9}$ Probable fluid movements within the remaining tubal segments would also favour implantation in tube. ${ }^{10}$

Mechanical failure of occlusion device is a theoretical possibility for failure of sterilization following breakage of ring / clip, due to poor quality. To avoid failure of band, fallopian tube is milked several times by drawing it in and out of the applicator sheath before application. At the end of laparoscopic sterilization, one must carefully look for a vertical crease between the two limbs of the loop and blanching to ensure complete occlusion of the fallopian tube. ${ }^{11}$

Trussell et al had sterilization failure more in the youngest age group (15-30) and it stabilised in the oldest age group (36-49). ${ }^{12}$ In the present study, the pregnancy after sterilization was highest in the age group (15-30) and stabilized in the oldest age group (36-49). Bilateral salpingectomy should be performed for an ectopic pregnancy resulting from sterilization failure. ${ }^{3}$

\section{CONCLUSION}

Female sterilization-failure is well known and proven entity and no age, method and interval is failure free.
Pregnancy after sterilization was higher $(77.6 \%)$ in the youngest age group (15-30) years than for the age group (31-35) years (18.7\%) and stabilized in the oldest age group (36-49) years. A positive correlation between age and interval of failure was found. The attributes that age and mode of gestation that spontaneous recanalisation and ectopic gestation of the post sterilization cases were independent. The sterilization failure occurred in less than one year was $6 \%$ and $3 \%$ cases were due to improper procedure was responsible for failure. Although, it is not completely preventable, failure due to improper procedure can be avoided if we will follow standard guidelines for tubal ligation.

The most common mode of sterilization failure was intrauterine pregnancy than the ectopic pregnancy and it was almost equal to each other. Therefore, proper counselling of patient prior to sterilization procedure should be done and patient should be explained about failure rates in terms of both intra and extra uterine pregnancy and early reporting if menses are delayed can help in diagnosing failure in early gestation and to reduce related morbidities. Surgical procedure should document presence of adhesions, endometriosis, and difficulty in identifying tubes, slipped ring or band. In spite of few failures, tubal ligation still remains the most chosen method to control population.

Funding: No funding sources

Conflict of interest: None declared

Ethical approval: The study was approved by the Institutional Ethics Committee

\section{REFERENCES}

1. Family Planning Beyond Sterilization in India[Internet]. Women Girls [cited 2017 Jun19]; Available https://www.newsdeeply.com/womenandgirls/article s/2016/06/09/family-planning -beyond-sterilizationin-india.

2. Sarella LK. Evaluation of post sterilization ectopic gestations. Int J Reprod Contracept Obstet Gynecol. 2017;6:1503-6.

3. Chakravarti S, Shardlow J. Tubal pregnancy after sterilization. Brit J Obstet Gynecol. 1975;82:58-60.

4. Rathod S, Samal SK. Clinical analysis of post sterilization failure cases in a tertiary hospital. Int $\mathbf{J}$ Reprod Contracept Obstet Gynecol. 2017 Jul 26;6(8):3294-6.

5. Brenner PF, Benedetti T, Mishell DR. Ectopic pregnancy following tubal sterilization surgery. Obstet Gynecol. 1977;49:323-4.

6. Thag M, Hassan H. A study on the prevalance and determinants of female sterilization failure in a tertiary health care centre in Thiruvananthapuram, Kerala. Indian J Res Paripex. 2015;4(5):477-81.

7. Vessey M, Huggins G, Lawless M, McPherson K, Yeates D. Tubal sterilization: Findings in a large 
prospective study. $\mathrm{Br} \quad \mathrm{J}$ Obstet Gynecol. 1983;90:203-9.

8. Rock JA, Parmley MA, King TM, Laufe LE, Su BC. Endometriosis and the development of tuboperitoneal fistulas after tubal ligation. Fertil Steril. 1981;35:16-20.

9. Hourine LH, O'Hara KE. Failed tubal sterilization as an ectopic factor in ectopic tubes pregnancy. Fertil Steril. 1978;29:509-11.

10. Stock RJ, Nelson KJ. Ectopic pregnancy subsquent to sterilization: histologic evalution and clinical implications. Fertil Steril. 1984;42:211-5.

11. Shah JP, Parulekar SV, Hinduja IN. Ectopic pregnancy after tubal sterilization. J Postgrad Med. 1991;37:17-20.
12. Trussell J, Guilbert É, Hedley A. Sterilization failure, sterilization reversal, and pregnancy after sterilization reversal in Quebec. Obstet Gynecol. 2003 Apr 1;101(4):677-84.

Cite this article as: Meena TS, Ramya KS, Mothilal R. Demographic and clinical analysis of post sterilization failure cases in a tertiary care hospital, Chennai, Tamil Nadu, India. Int J Reprod Contracept Obstet Gynecol 2017;6:4976-80. 